\title{
Juvenile nasopharyngeal angiofibroma with intracranial extension - A review of 29 cases
}

\author{
Varun Jain, Surya Kumar Dube, Charu Mahajan', Hemanshu Prabhakar
}

\begin{abstract}
Background: Complete resection has been the preferred treatment for extracranial juvenile nasopharyngeal angiofibromas (JNA) but resection of JNA with intracranial extension (ICE) can be quite challenging because of the associated risk of extensive haemorrhage. The aim of this study was to assess the neurological outcome of patients undergoing surgery for removal of JNA with ICE and analyse various perioperative anaesthetic factors that could possibly affect the outcome. Materials and Methods: This retrospective study was conducted including patients with JNA with ICE requiring combined otolaryngological and neurosurgical approach for tumour removal at our centre from January $200 \mathrm{I}$ to December 20 I0. Patient's medical and anaesthesia records were reviewed and data regarding patient demography, pre-operative investigations, anaesthetic management, post-operative investigations and complications, number of days of intensive care unit (ICU) and hospital stay and Glasgow Outcome Scale (GOS) at the time of discharge from hospital were collected and reviewed. Results: A total of 29 patients were operated. The median age of presentation was I5 years. Nineteen patients (65.5\%) had a good GOS of 5 at discharge, 7 (24.1\%) had moderate outcome with GOS of 4 and 3 patients ( $10.3 \%$ ) had poor outcome with GOS of $\leq 3$. There was one mortality in our study. Perioperative factors affecting the GOS at discharge were amount of intra-operative blood loss, intra-operative infusion of packed red blood cells (RBCs) and colloid and post-operative haemoglobin. Conclusion: The outcome of patients with JNA is affected by intra-operative blood loss and transfusion.
\end{abstract}

Key words: Anaesthesia, blood loss, juvenile nasopharyngeal angiofibroma, outcome

\section{INTRODUCTION}

Juvenile nasopharyngeal angiofibroma (JNA) is a benign, locally invasive, highly vascular tumour that arises from the lateral wall or the roof of the nasopharynx especially the sphenopalatine foramen. ${ }^{[1-4]}$ JNA accounts for approximately $0.5 \%$ of all head and neck neoplasms. ${ }^{[3]}$ The median age at diagnosis is 15 years and occurs exclusively in adolescent males. ${ }^{[4]}$

\begin{tabular}{|l|l|}
\hline \multicolumn{2}{|c|}{ Access this article online } \\
\hline Quick Response Code: & Website: \\
\hline & www.jnaccjournal.org \\
\cline { 2 - 2 } & \\
\hline
\end{tabular}

As the tumour grows, it extends into the maxillary, ethmoid and sphenoid sinuses, the nasopharynx, and laterally into the infratemporal fossa. Intracranial invasion into the middle fossa commonly occurs through the pterygomaxillary space and the tumour may erode superiorly into the sella and anterior skull base. Approximately $20 \%$ of patient of JNA have evidence of skull base invasion at the time of diagnosis. ${ }^{[3]}$ The blood supply to the tumour is mainly from external carotid artery but draws feeder from internal carotid artery as the tumour extends intracranially. The tumour consists of proliferating irregular blood vessels that characteristically lack smooth muscle and elastic fibres making its notorious for sustained bleeding.

Complete resection has been the preferred treatment for extracranial JNAs, ${ }^{[4]}$ but resection of JNA with intracranial extension (ICE) can be quite challenging

Department of Neuroanaesthesiology, Neurosciences Center, All India Institute of Medical Sciences, New Delhi, ${ }^{1}$ Department of Anaesthesia, Sanjay Gandhi Post Graduate Institute of Medical Sciences, Lucknow, India

Address for correspondence:

Dr. Hemanshu Prabhakar, Department of Neuroanaesthesiology, Neurosciences Center, All India Institute of Medical Sciences, New Delhi - 110029 , India. E-mail: prabhakarhemanshu@rediffmail.com 
both for the anaesthesiologists and the surgeons mainly because of the associated risk of extensive haemorrhage. The advancement in anaesthesiology and diagnostic imaging techniques and pre-operative angiographic embolisation has contributed towards the successful management of JNA with ICE. The aim of this study was to assess the neurological outcome of patients undergoing surgery for removal of JNA with ICE and analyse various perioperative anaesthetic factors that could possibly affect the outcome.

\section{MATERIALS AND METHODS}

After obtaining Institute Ethics Committee approval, this retrospective study was conducted including patients with JNA with ICE requiring combined otolaryngological and neurosurgical approach for tumour removal at our centre from January 2001 to December 2010. All patients with Radkowski classification [Table 1] Grade III tumour extension referred to the Neurosurgery department were studied. Patient's medical and anaesthesia records were reviewed and data regarding patient demography, pre-operative investigations, anaesthetic management, post-operative investigations and complications, number of days of intensive care unit (ICU) and hospital stay and Glasgow Outcome Scale (GOS) [Table 2] at the time of discharge from hospital were collected and

\section{Table 1: Radkowski classification of juvenile angiofibromas}

\begin{tabular}{ll}
\hline Stage & Details \\
\hline IA & Limited to the nose and nasopharyngeal area \\
IB & Extension into one or more sinuses \\
IIA & $\begin{array}{l}\text { Minimal extension into pterygopalatine fossa } \\
\text { IIB }\end{array}$ \\
& $\begin{array}{l}\text { Occupation of the pterygopalatine fossa without } \\
\text { orbital erosion }\end{array}$ \\
IIC & $\begin{array}{l}\text { Infratemporal fossa extension without cheek or } \\
\text { pterygoid plate involvement }\end{array}$ \\
IIIA & $\begin{array}{l}\text { Erosion of the skull base (middle cranial fossa or } \\
\text { pterygoids) }\end{array}$ \\
IIIB & $\begin{array}{l}\text { Erosion of the skull base with intracranial extension } \\
\text { with or without cavernous sinus involvement }\end{array}$ \\
\hline
\end{tabular}

\section{Table 2: Glasgow outcome scale}

\footnotetext{
1. Dead

2. Vegetative state, unable to interact with environment; unresponsive

3. Severe disability, able to follow commands/unable to live independently

4. Moderate disability, able to live independently; unable to return to work or school

5. Good recovery, able to return to work or school
}

reviewed. Various parameters were correlated with GOS. For the purpose of analysis, GOS was divided into three categories: GOS $\leq 3$ (poor), GOS 4 (moderate) and GOS 5 (good).

\section{Anaesthesia Protocol}

A standard management protocol was followed for all patients. All patients were assessed one day prior to proposed surgery and adequate blood and blood products were arranged. Patients who had intra-arterial embolisation for the tumour were taken up for surgery within $48 \mathrm{~h}$ of procedure. Standard monitors including electrocardiography (ECG), pulse oximetry $\left(\mathrm{SPO}_{2}\right)$, non-invasive $\mathrm{BP}(\mathrm{NIBP})$, end tidal carbon dioxide $\left(\mathrm{ETCO}_{2}\right)$ and nasopharyngeal temperature were used in all patients. In all patients general anaesthesia (GA) was induced with either propofol or thiopentone with fentanyl and rocuronium and was maintained with oxygen, nitrous oxide and isoflurane/sevoflurane with intermittent boluses of fentanyl and vecuronium. Arterial line and central venous cannulation was done in all cases for invasive blood pressure (IBP) and central venous pressure (CVP) monitoring. Two wide bore peripheral intravenous accesses were secured in all the patients. Patients were placed in reverse tredelenberg position and mechanical ventilation was adjusted to ETCO2 of $33 \pm 2 \mathrm{mmHg}$. Arterial blood gas (ABG) analysis was performed routinely post-induction (baseline $\mathrm{ABG}$ ) and frequently thereafter, correlating with the episodes of heavy blood loss.

Goals for anaesthesiologist were to provide stable intra-operative haemodynamics, to keep the mean BP at lower normal range of $50-70 \mathrm{mmHg}$. Blood loss calculation and fluid replacement was as per the senior anaesthesiologist's assessment. Blood loss was calculated by assessing the collected blood in the surgical field, suction bottles, soaked mops and serial ABGs. Fluid replacement was judged on the basis of pre-operative haemoglobin, blood loss, urine output, hemodynamic stability and ABG analysis. We used ringer lactate and $0.9 \%$ normal saline (each litre alternatively) and $6 \%$ hydroxyethyl starch (HES) as intravenous fluid. Cell saver was available for every case but its usage was at the discretion of the surgeon. Blood transfusion was started when haemoglobin fell below $8 \mathrm{~g} / \mathrm{dl}$ and patient showed signs of hemodynamic instability. Autologous blood was transfused prior to allogenic blood when available. At the end of surgery all the anaesthetics were discontinued and patient's trachea was extubated or patients were shifted with the endotracheal tube in situ for further management to the neurosurgical ICU. Any coagulation, haematological or electrolyte disturbances in the post-operative period was managed with standard management protocol. In intubated patients, tracheal extubation was planned in discussion with neurosurgical team after confirming hemodynamic 
stability, satisfactory clinical neurological condition and radiological review.

\section{Data Collection}

Various pre-operative parameters recorded were demographic data (age, gender, weight and blood group), recurrence, number of previous surgeries for removal of angiofibroma, history of embolisation and baseline investigations (haemoglobin, platelets and coagulation profile), intra-operative data (duration of surgery, type of anaesthetic techniques, amount of blood loss, amount of fluids infused, use of cell saver and autologous blood transfused, anaesthesia and surgical duration, ABG and other investigation reports and extubation details), post-operative details (post-operative haemoglobin, coagulation profile, post-operative blood transfusion, number of days on ventilator and duration of ICU and hospital stay). Post-operative recovery was assessed using GOS score by the neurosurgical team at discharge.

\section{Statistical Analysis}

Statistical analysis was done using the software SPSS version 15.0 (Illinois, Chicago, USA). The data is presented in median (range) or number (percentage). The numerical data was categorised and compared using Kruskal-Wallis test. The significant result was compared by post-hoc comparison with probability adjustment. Strength of correlation between blood loss and fluid infused was by Spearman's rank correlation coefficient. Categorical data (blood group, use of cell saver, embolisation history, history of previous surgery and type of induction agent used) and GOS were tested using Mann-Whitney Wilcoxon test. The $P<0.05$ is considered significant.

\section{RESULTS}

A total of 29 patients were operated from 2001 to 2010 at our centre with Grade III Radkowski JNA requiring combined otolaryngological and neurosurgical approach for dissection and removal of JNA with ICE. A total of 19 patients $(65.5 \%)$ had a good GOS of 5 at discharge,
$7(24.1 \%)$ had moderate outcome with GOS of 4 and 3 patients $(10.3 \%)$ had poor outcome with GOS of $\leq 3$. There was one mortality in our study.

\section{Demographic and Pre-Operative Data}

All the patients were males and the median age of presentation was 15 years with range of 8-29 years [Table 3]. Median weight of patients was about $43 \mathrm{~kg}$ with range of $22-60 \mathrm{~kg}$. A total of 20 patients $(69 \%)$ had undergone at least one surgery previously and this time presented with a recurrence, whereas the remaining 9 patients presented first time for surgery. No other co-morbidity was present in any of the patients and all the patients had full Glasgow Coma Scale score at presentation (Eye 4, Verbal 5, Motor 6). Two of the patients received tablet flutamide pre-operatively in our study. A total of 19 patients (65.52\%) had intra-arterial embolisation of tumour before surgery. Median baseline haemoglobin, INR and platelet count of patients were $12.7 \mathrm{~g} / \mathrm{dl}, 1.09$ and $233000 / \mathrm{mm}^{3}$, respectively. All the above demographic data and pre-operative work-up of patients was statistically correlating, although there was a trend towards the younger age group, showing better GOS at discharge.

\section{Operative Data}

GA was induced with either propofol (18 patients) or thiopentone (11 patients). Median duration of surgery was $6.75 \mathrm{~h}$. Patients with GOS 5 had a shorter surgical time of $6.1 \mathrm{~h}$ compared with patients with GOS $4(7.5 \mathrm{~h})$ and GOS $\leq 3(8.16 \mathrm{~h})$. Median blood loss was $2500 \mathrm{ml}$ (600-9400 ml). Increasingly higher blood loss was noticed in patients with poorer GOS. Median blood loss in patients with GOS 5 was $2000 \mathrm{ml}$, compared with $4000 \mathrm{ml}$ in patients with GOS 4 and $8000 \mathrm{ml}$ in patients with GOS $\leq 3(P=0.023)$ [Table 4]. Patients who had intra-arterial embolisation pre-operatively had lesser intra-operative blood loss (median $2100 \mathrm{ml}$ ) compared with those not embolised (median $2900 \mathrm{ml}$ ); data was, however, statistically not significant $(P=0.696)$. Similarly, patients embolised needed 3 units (range 2-9 units) packed red blood cells (RBCs) transfusion compared with 5.5 units (range 0-11 units) in non-embolised

Table 3: Demographic and Pre-operative baseline characteristics

\begin{tabular}{|c|c|c|c|c|c|}
\hline GOS & Total $(N=29)$ & $\leq 3(N=3)$ & $4(N=7)$ & $5(N=19)$ & $P$ value \\
\hline Age (years) & $15(8-29)$ & $19(15-22)$ & $18(14-26)$ & $14(8-29)$ & 0.11 \\
\hline Weight (kg) & $43(22-60)$ & $40(30-46)$ & $47(40-60)$ & $43(22-60)$ & 0.32 \\
\hline Recurrence & 20 & 1 & 6 & 13 & 0.25 \\
\hline Embolisation & $19(65.5 \%)$ & $1(33.3 \%)$ & $5(71.4 \%)$ & $13(68.4 \%)$ & 0.46 \\
\hline Haemoglobin $(\mathrm{g} \%)$ & $12.7(10-16.4)$ & $12.1(10-16.4)$ & $12.7(11.1-14.1)$ & $13(10.2-15.2)$ & 0.98 \\
\hline Baseline INR & $1.09(0.9-1.2)$ & $1.09(1-1.2)$ & $1.08(1-1.1)$ & $1.1(0.9-1.2)$ & 0.64 \\
\hline Baseline Plt (*105/mm3) & $2.33(1.71-3.12)$ & $3.02(1.98-3.1)$ & $2.1(1.85-3.12)$ & $2.37(1.71-3.12)$ & 0.38 \\
\hline
\end{tabular}

[data presented in median (range)], GOS = Glasgow outcome scale, $N=$ Number of patients, INR = International normalised ratio, PIt $=$ Platelets 
Jain, et al.: Juvenile nasopharyngeal angiofibroma with intracranial extension

Table 4: Intra-operative parameters and glasgow outcome scale

\begin{tabular}{lccccc}
\hline GOS & Total $(\mathbf{N = 2 9 )}$ & \multicolumn{1}{c}{$\mathbf{3}(\mathbf{N = 3})$} & $\mathbf{4}(\mathbf{N}=7)$ & $\mathbf{5}(\mathbf{N = 1 9 )}$ & $\boldsymbol{P}$ value \\
\hline Duration of Sx (h) & $6.75(5.0-9.5)$ & $8.16(5.16-9.5)$ & $7.5(5.5-8.0)$ & $6.16(5.0-9.2)$ & 0.47 \\
Blood loss (ml) & $2500(600-9400)$ & $8000(2500-9400)$ & $4000(1300-7000)$ & $2000(600-4800)$ & 0.02 \\
Cell saver & $17(58.6 \%)$ & $2(66.7 \%)$ & $3(42.9 \%)$ & $12(63.2 \%)$ & 0.62 \\
Autologous & $200(0-3800)$ & $2000(0-3000)$ & $0(0-3800)$ & $490(0-1500)$ & 0.35 \\
RBC (units) & $4(0-11)$ & $6(5-7)$ & $6(2-11)$ & $3(0-7)$ & 0.04 \\
FFP (units) & $2(0-8)$ & $0(0-8)$ & $4(0-6)$ & $2(0-5)$ & 0.13 \\
PRP (units) & $0(0-8)$ & $0(0-8)$ & $0(0-7)$ & $2(0-4)$ & 1.0 \\
Crystalloids (ml) & $5500(3000-10000)$ & $8000(4000-9000)$ & $7500(4500-10000)$ & $5000(3000-9000)$ & 0.05 \\
Colloid (ml) & $700(0-2000)$ & $2000(1000-2000)$ & $500(0-1500)$ & $500(0-1000)$ & 0.046 \\
\hline
\end{tabular}

[data presented in numbers (percentage)] GOS $=$ Glasgow outcome scale, $N=$ Number of patients, $\mathrm{Sx}=$ Surgery, RBC $=$ Red blood cells, FFP = Fresh frozen plasma, $\mathrm{PRP}=$ Platelet rich plasma

patients, although data was again statistically insignificant $(P=0.2627)$. Overall, median 4 units of blood, 2 units fresh frozen plasma (FFP), 5.5 L crystalloid and $700 \mathrm{ml}$ colloid was transfused in all the cases. Generally, no median plasma rich platelets (PRP) were transfused intra-operatively. Packed RBCs transfusion was less in GOS 5 patients ( 3 units) compared with GOS 4 and GOS $\leq 3$ patient group (median 6 units each). Lower crystalloid requirements were noted in GOS 5 group (5000 ml) as against $7500 \mathrm{ml}$ in GOS 4 group and $8000 \mathrm{ml}$ in GOS $\leq 3$ group. Similarly, colloid transfusion was less in GOS 5 and GOS 4 category patients (median $500 \mathrm{ml}$ ) compared with about $2000 \mathrm{ml}$ in GOS $\leq 3$ category patients. Cell saver was employed in 17 (58.6\%) of 29 cases. Mean blood loss when cell saver was used was $3670 \pm 2380 \mathrm{ml}$ compared with $2433.3 \pm 1683 \mathrm{ml}$ in patients where cell saver was not used $(P=0.143)$. Mean amount of packed RBCs transfused in patients where cell saver was used was 4.3 units compared with 4.6 units where cell saver was used $(P=0.322)$. However, a positive correlation between blood loss and amount of autologous blood transfused existed ( $P=<0.0001)$. Packed RBCs transfusion correlated positively with the amount of blood loss $(P=<0.0001)$ irrespective of cell saver usage. Metabolic acidosis (37.9\%), hypocalcaemia (10.3\%) and hyperkalemia $(10.3 \%)$ were the most commonly encountered metabolic and electrolyte abnormality in our series.

\section{Post-Operative Data}

At the end of surgery, all patients except one were shifted to ICU for elective ventilation. One patient was extubated in the operating room. This was a 28-year-old male with an early ICE of tumour. Intra-operative, this patient had $600 \mathrm{ml}$ blood loss and had a stable hemodynamic course. There was one mortality (GOS1) of a 15-year-old male weighing $30 \mathrm{~kg}$. The patient had undergone surgery twice previously and incurred blood loss of $8000 \mathrm{ml}$ (maximum per $\mathrm{kg}$ blood loss in this retrospective data) and succumbed to hypovolemic haemorrhagic shock. The median post-operative haemoglobin was $10.9 \mathrm{~g} / \mathrm{dl}$ and INR 1.10. Post-operative haemoglobin correlated with GOS at discharge $(P=0.047)$ [Table 5]. No blood was transfused in ICU to patients who had GOS 5 at discharge, but median 1 and 2 units were transfused to patients with GOS 4 and GOS $\leq 3$, respectively. However, the difference was statistically insignificant. Patients with GOS 4 and GOS 5 were electively ventilated for approximately $12 \mathrm{~h}$ post-operatively and were tracheally extubated next morning. Median ICU stay for these patients was 2 days. However, patients with GOS $\leq 3$ were ventilated for 3 days (median, maximum 5 days) and had an ICU stay for 7 days. None of the patients needed re-intubation. The median hospital stay was 5 days.

An interesting finding in our study was that all three patients with GOS $\leq 3$ were blood group A-positive but rest of the patients with GOS 4 and GOS 5 had a higher incidence of blood group B-positive. Overall, there was a higher incidence of JNA with ICE in blood group B-positive patients (51.7\%) [Table 6].

\section{DISCUSSION}

Primary findings of our study were that majority of patients undergoing surgery for JNA with ICE (Radowski classification grade III) had a good neurological outcome. Only $10.3 \%$ of patients had poor neurological outcome at discharge with a GOS score of $\leq 3$. Perioperative factors affecting the GOS at discharge were amount of intra-operative blood loss, amount of fluid infused intra-operatively especially packed RBCs and colloid and post-operative haemoglobin. Secondary findings in our analysis showed that intra-arterial embolisation of tumour pre-operatively reduces the intra-operative blood loss and amount of blood transfused; although the findings were not statistically significant. Intra-operative use of cell saver may be useful in reducing the amount of allogenic blood transfused. 
Table 5: Post-operative parameters and glasgow outcome scale

\begin{tabular}{lccccc}
\hline GOS & Total $(\mathbf{N = 2 9})$ & $\leq \mathbf{3}(\mathbf{N}=\mathbf{3})$ & $\mathbf{4}(\mathbf{N}=\mathbf{7})$ & $\mathbf{5}(\mathbf{N}=\mathbf{1 9})$ & $\boldsymbol{P}$ value \\
\hline Post-op $\mathrm{Hb}(\mathrm{g} \%)$ & $10.9(3.8-3.5)$ & $6.3(3.8-11.6)$ & $10.1(6.9-11.3)$ & $11(9.2-13.5)$ & 0.04 \\
Post-op INR & $1.1(0-5)$ & $2.9(0-5)$ & $1.1(1-2.1)$ & $1.1(1-2.6)$ & 0.41 \\
Post op BT (units) & $0(0-3)$ & $2(0-3)$ & $1(0-3)$ & $0(0-3)$ & 0.26 \\
Ventilatory days & $0.5(0-5)$ & $3(0.5-5)$ & $0.5(0.5-2)$ & $0.5(0-2)$ & 0.19 \\
ICU stay (days) & $2(1-8)$ & $7(1-8)$ & $2(2-4)$ & $2(1-4)$ & 0.26 \\
Hospital stay (days) & $5(1-10)$ & $5(1-10)$ & $5(4-7)$ & $5(3-7)$ & 0.39 \\
\hline
\end{tabular}

[data presented in median (range)], GOS = Glasgow outcome scale, INR = International normalised ratio, ICU = Intensive care unit

Table 6: Blood group and glasgow outcome scale

\begin{tabular}{lccc}
\hline Blood & \multicolumn{3}{c}{ GOS $(\%)$} \\
\cline { 2 - 4 } group & $\leq \mathbf{3}(\mathbf{N = 3 )}$ & $\mathbf{4}(\mathbf{N = 7 )}$ & $\mathbf{5}(\mathbf{N = 1 9 )}$ \\
\hline A-positive & $3(100)$ & $2(28.6)$ & $3(15.8)$ \\
B-positive & 0 & $4(57.1)$ & $11(57.9)$ \\
AB-positive & 0 & $1(14.3)$ & $2(10.5)$ \\
O-positive & 0 & 0 & $2(10.5)$ \\
O-negative & 0 & 0 & $1(5.3)$ \\
\hline
\end{tabular}

[data presented in numbers (percentage)], GOS = Glasgow outcome scale, $N=$ Number of patients

The demographical data reviewed from this retrospective study are comparable to studies done previously. ${ }^{[5,6]}$ In this study, the typical presentation of angiofibroma is an adolescent male with an median age of 15 years and median weight of $43 \mathrm{~kg}$. Effect of craniofacial surgery necessary for removal of intra-cranially spread JNA on neurological outcome has not been studied previously because of the fact that JNA is primarily a head and neck tumour and it is assumed that neurological outcome will be good. We have shown for the first time that such an extensive intracranial surgery can have an effect on neurological status of a patient. Although majority of cases $(65.5 \%)$ had a good neurological outcome of GOS 5, $24.1 \%$ of cases had a decrease in neurological outcome with a GOS of 4 and $10.3 \%$ of cases had a poor GOS of $\leq 3$. Mortality has been associated with such an extensive surgery when accompanied with massive haemorrhage ${ }^{[4,6]}$ Our study also witnessed one mortality associated with JNA surgery. The patient had massive uncontrollable blood loss intra-operatively, which was maximum observed blood loss in this study $(266.7 \mathrm{ml} / \mathrm{kg}$ body weight).

Recurrence has been suggested as a major complication in greater part of surgical literature, ${ }^{[6-9]}$ despite the benign and unifocal origin of JNA. Tumour recurrence is primarily seen with high grade tumours with ICE, in part, due to failure to recognise skull base erosion. ${ }^{[3,10]}$ Recurrence rate for JNA has been reported from $17 \%$ to $86 \%{ }^{[9,11]}$ For 20 of $29(69 \%)$ patients in our study, there was a recurrence. For six of these cases, there was multiple recurrence and they had been operated at least twice previously. This recurrence is higher than that reported in literature but since this depicted the recurrence rate in patients who were referred to the neurosurgical department at our institute, this probably does not reflect the complete picture. Rather it emphasis the fact JNA can reappear as a higher grade tumour.

Intra-operative blood loss has been most troublesome aspect in management of JNA. Median blood loss in our study was $2500 \mathrm{ml}$ (range 600-9400 ml). Moulin et al. ${ }^{[12]}$ compared intra-operative blood loss in embolised and non-embolised patients undergoing surgery for JNA removal. In their study, the mean blood loss was $5380 \mathrm{ml}$ in patients without embolisation and $1037 \mathrm{ml}$ in those with embolisation. Ezri et al.$^{[13]}$ found the blood loss in non-embolised patients undergoing surgery for removal of JNA was $4800 \pm 1600 \mathrm{ml}$. Bales et al. ${ }^{[3]}$ reported lower blood loss in five patients who had a craniofacial resection and observed a mean blood loss of $1120 \mathrm{ml}$ (range, 700-1750 ml). In our series, excessive blood loss was the major perioperative factor, which influenced the GOS. Patients with good GOS (5) had lower blood loss intra-operatively compared with patients with poorer GOS (4 and $\leq 3$ ).

Various techniques are helpful in reducing the intra-operative blood loss like use of reverse trendelenberg position, hypotensive anaesthesia ${ }^{[13]}$ and embolisation of the tumour. We employed reverse trendelenberg position in all our patients and the aim was to keep the mean blood pressure in the range of 55$65 \mathrm{mmHg}$ by titration of inhalation agent. Embolistion of tumour was done in $65.5 \%$ of patients pre-operatively and all the patients were taken up for surgery within $48 \mathrm{~h}$ as consistent with other studies. ${ }^{[6,14]}$ There was no uniform consensus among surgeons at our institute about embolisation of tumour as embolisation though reduces blood loss may prevent complete evacuation of tumour. Embolistion of tumour was helpful in decreasing amount of packed RBCs transfused intra-operatively (3 units) versus 5.5 units in non-embolised tumours. This was similar to findings by Mann et al. ${ }^{[3]}$ in their 12-year study. However, pre-operative embolisation did not seem to influence the GOS directly. 
Two of our patients received flutamide in the preoperative period. Flutamide (2-methyl-n-[4-nitro-3 \{trifluoromethyl\} phenyl] propanamide) is an orally active non-steroidal androgen antagonist (NSAA) a non-steroidal anti-androgen drug administrated orally and is widely used in the treatment of cancer of the prostate. ${ }^{[15,16]}$ There are conflicting reports regarding the usefulness of its use to reduce the size of JNA in the literature. Gates et al. ${ }^{[17]}$ and Thakar et al. ${ }^{[15]}$ reported reduction of JNA size in their studies. However, in another study by Labra et al., ${ }^{[16]}$ the authors did not find any significant reduction in the JNA size. Nausea, hepatotoxicity and mild breast tenderness are the common reported side effects of flutamide and regular liver function test has to be done in patients receiving flutamide. ${ }^{[15]}$ The probability of hepatic derangement is to be taken into consideration in patients receiving flutamide.

Besides techniques to reduce blood loss, other useful method of preserving blood is by use of cell saver. In our study, although the amount of blood loss was statistically similar whether cell saver is used or not, it was clinically much less in the group where cell saver was not used. Considering that packed RBCs were transfused in both groups equally, and there was positive correlation of blood loss and amount of autologous blood transfused proves that patients in whom cell saver was employed were saved of excessive allogenic blood transfusion. It is therefore judicious to use cell saver where major blood loss is expected. Again use of cell saver did not influence the GOS directly.

Lastly, factor affecting the GOS was haemoglobin in the post-operative period; higher haemoglobin value was associated with better neurological outcome. A cautious approach in the post-operative period regarding extubation is warranted in these patients because of the risk of aspiration due to inadequate haemostasis, coagulation disorder and airway oedema associated with prolonged surgery and tumour handling. Therefore, all but one patient were shifted intubated in ICU post-operatively and extubation was planned after confirmation with surgeons about haemostasis. No re-intubation was needed in any of the patients.

To summarise, our study on 29 patients of JNA with ICE undergoing tumour resection via combined otolaryngolocial and neurosurgical approach showed that outcome of patients was affected by intra-operative blood loss and fluid management, a basic but important clinical skill for all anaesthesiologists. This study also highlights the fact that it is important to replace the blood timely and adequately in surgeries where major blood loss occurs.

\section{REFERENCES}

1. Martin H, Ehrlich HE, Abels JC. Juvenile nasopharyngeal angiofibroma. Ann Surg 1948;127:513-36.

2. Herman P, Lot G, Chapot R, Salvan D, Huy PT. Long term follow-up of juvenile nasopharyngeal angiofibromas: Analysis of recurrences. Laryngoscope 1999;109:140-7.

3. Bales C, Kotapka M, Loevner LA, Al-Rawi M, Weinstein G, Hurst R, et al. Craniofacial resection of advanced juvenile nasopharyngeal angiofibroma. Arch Otolaryngol Head Neck Surg 2002;128:1071-8.

4. Bremer JW, Neel HB $3^{\text {rd }}$, DeSanto LW, Jones GC. Angiofibroma: Treatment trends in 150 patients during 40 years. Laryngoscope 1986;96:1321-9.

5. Tewfik TL, Tan AK, al Noury K, Chowdhury K, Tampieri D, Raymond J, et al. Juvenile nasopharyngeal angiofibroma. J Otolaryngol 1999;28:145-51.

6. Mann WJ, Jecker P, Amedee RG. Juvenile angiofibromas: Changing surgical concept over the last 20 years. Laryngoscope 2004;114:291-3.

7. Gupta AC, Murthy DP. Intracranial juvenile nasopharyngeal angiofibroma. Aust N Z J Surg 1997;67:477-82.

8. Tang IP, Shashinder S, Gopala Krishnan G, Narayanan P. Juvenile nasopharyngeal angiofibroma in a tertiary centre: Ten-year experience. Singapore Med J 2009;50:261-4.

9. Elsharkawy AA, Kamal EM, Tawfik A, Zaher A, Kasem M. Juvenile nasopharyngeal angiofibroma with intracranial extension: Analysis of 23 Egyptian patients. Int J Pediatr Otorhinolaryngol 2010;74:755-9.

10. Donald PJ, Enepikedes D, Boggan J. Giant juvenile nasopharyngeal angiobroma: Management by skull-base surgery. Arch Otolaryngol Head Neck Surg 2004;130:882-6.

11. Deschler DG, Kaplan MJ, Boles R. Treatment of large juvenile nasopharyngeal angiobroma. Otolaryngol Head Neck Surg 1992;106:278-84.

12. Moulin G, Chagnaud C, Gras R, Gueguen E, Dessi P, Gaubert JY, et al. Juvenile nasopharyngeal angiofibroma: Comparison of blood loss during removal in embolized group versus nonembolized group. Cardiovasc Intervent Radiol 1995; 18:158-61.

13. Ezri T, Roth Y, Geva D, Konichezky S, Marshak G, Halperin D. anesthetic management of juvenile nasopharyngeal angiobroma resection. J Cardiothorac Vasc Anesth 2003;17:622-4.

14. Nicolai P, Berlucchi M, Tomenzoli D, Cappiello J, Trimarchi M, Maroldi R, et al. Endoscopic surgery for juvenile angiofibroma: When and how. Laryngoscope 2003;113:775-82.

15. Thakar A, Gupta G, Bhalla AS, Jain V, Sharma SC, Sharma R, et al. Adjuvant therapy with flutamide for presurgical volume reduction in juvenile nasopharyngeal angiofibroma. Head Neck 2011;33:1747-53.

16. Labra A, Chavolla-Magaña $R$, Lopez-Ugalde A, Alanis-Calderon J, Huerta-Delgado A. Flutamide as a preoperative treatment in juvenile angiofibroma (JA) with intracranial invasion: Report of 7 cases. Otolaryngol Head Neck Surg 2004;130:466-9.

17. Gates GA, Rice DH, Koopmann CFJr, Schuller DE. Flutamide induced regression of angiofibroma. Laryngoscope 1992;102:641-4.

How to cite this article: Jain V, Dube SK, Mahajan C, Prabhakar H. Juvenile nasopharyngeal angiofibroma with intracranial extensionA review of 29 cases. J Neuroanaesthesiol Crit Care 2014;1:40-5.

Source of Support: Nil, Conflict of Interest: None declared. 